\title{
Market potential of TikTok in the context of the communication range of soccer players on social networks
}

\author{
Jan Šíma
}

\author{
Department of Sport Management, Faculty of Physical Education and Sport, Charles University, Prague, \\ Czech Republic \\ sima@ftvs.cuni.cz
}

\begin{abstract}
The study aims to put the social network TikTok into the context of the marketing attractiveness and potential of soccer players in terms of communication range through social networks. Soccer clubs can assess the expenses of gaining additional followers through a purchased player by an evaluation of the market efficiency of individual soccer players' followers. The study also documents positive effects ensuing from the acquisition of further followers thanks to the purchase of such a player including image, connection with fans, global reach, additional external funds through sponsorship and the sale of television rights, loyal fans and other so-called "extra-football qualities". The study thus brings new perspectives on TikTok, as a network which has so far not been thoroughly researched, in the field of the most popular sport in the world, soccer.
\end{abstract}

\section{KEYWORDS}

TikTok; soccer players; social media; market value; market efficiency; penetration of social network

DOI

10.14712/23366052.2021.13

\section{INTRODUCTION}

TikTok is a social network which is currently experiencing a considerably higher growth in popularity, users and number of downloads than other contemporary social networks, primarily Facebook, Twitter and Instagram (Omnicore.com, 2020; Datareportal: Digital 2020, 2020; Socialbakers.com, 2020; Statista.com, 2020), where purely communication platforms used by these networks, such as WhatsApp and Facebook Messenger, are not taken into consideration. The use of Twitter is, unlike Facebook and Instagram (networks which are the subject of research), vastly different in various countries, as Özsoy (2011) and Yoon, Petrick, \& Backman (2017) have shown in studies from Turkey and the USA. Nevertheless, it ranks together with these among the three most used social networks for communicating with sports fans (Mogale, 2020;

(c) 2021 The Author. This is an open-access article distributed under the terms of the Creative Commons Attribution License (http://creativecommons.org/licenses/by/4.0), which permits unrestricted use, distribution, and reproduction in any medium, provided the original author and source are credited. 
Yoon, Petrick, \& Backman, 2017). TikTok currently has around 800 million users (Omnicore.com, 2020; Datareportal: Digital 2020, 2020; Socialbakers.com, 2020; Statista.com, 2020). TikTok has a strong influence on people's behaviour, especially those of a young age (Mogale, 2020), much as has long been the case for other social networks (Shoham et al., 2012). With regard to the expected development on social networks (Omnicore.com, 2020; Datareportal: Digital 2020, 2020; Socialbakers. com, 2020; Statista.com, 2020) it is desirable to include TikTok among relevant social network-based communication channels, both from the perspective of marketing communication in general, and from the perspective of marketing communication of the most widespread and most popular sport in the world, i.e., football/soccer (Müller, Simons, \& Weinmann, 2017; WorldAtlas.com, 2020; TotalSportek.com, 2020; BiggestGlobalSports.com, 2020). Soccer players, as the sport's main participants, are thereby provided with another means of communicating directly with their supporters, fans and the public without misrepresentation of information by the mass media (Gibbs, O’Reilly, \& Brunette, 2014; Özsoy, 2011; Hambrick, et al., 2010). The study actually focuses on the inclusion of the social network TikTok, as the currently fastest growing form of social media, in the context of marketing attractiveness and potential of soccer players in terms of communication range through social networks.

\section{THEORETICAL BACKGROUND}

Today, social networks are an inseparable part of the marketing communication of not only all professional sports teams and clubs (Anagnostopoulos, Parganas, Chadwick, \& Fenton, 2018; Watanabe, Yan, \& Soebbing, 2016; Vale \& Fernandes, 2018; Yoon, Petrick, \& Backman, 2017), but also of individual athletes themselves, soccer players in particular (Li \& Huang, 2015; Sanderson, 2013; Müller, Simons, \& Weinmann, 2017; Pérez, 2013; Gibbs, O’Reilly, \& Brunette, 2014; Tiago, et al., 2016). Within the scope of sporting entity marketing communication, social networks can be used for various marketing objectives. Anagnostopoulos, Parganas, Chadwick, \& Fenton (2018) point out the effect of Instagram for strengthening the brand performance of soccer clubs in the English Premier League through considerable and increasing fan engagement, and thereby increasing congruence between a soccer club's desired and perceived brand image. As well as brand image, the need for information on the brand, brand empowerment and love for a brand are other driving forces for the use of social networks in sports marketing for building a fan base (Vale \& Fernandes, 2018). Information directly from sports brands (clubs, teams and individuals), and the associated increase of credibility, involvement and attractiveness, significantly strengthens fan loyalty to the brand (Yoon, Petrick, \& Backman, 2017). The more fans a sporting entity has, the more attractive it will be for obtaining external sources of funding, which are provided by sponsors/business partners, the media through the purchase of broadcasting rights, and other spectators and potential fans (Pieters, Knoben, \& Pouwels, 2012). Followers on social networks also act as further opinion leaders and propagators of communications, through their contacts, to other recipients, thus increasing communication ranges through the profiles of athletes in social networks even further (Araujo, 2019). Followers and fans are essentially "co-producers" of a sports product and salient stakeholders in the value co-creation process (Zagnoli \& Radicchi, 2010). 
Since interaction and communication on social networks is a very dynamic process, sporting entities have to work with these tools both strategically and in view of the overall organisational goals of the team, club or individual (Watanabe, Yan, \& Soebbing, 2016). When strategically planning communication on social networks, it is important to pay particular attention to the production of creative content relating to specific events on the particular entity's sporting calendar, and also to pay attention to perspectives and reviews after such events, as these are important factors for the positive development of the number of followers on social networks (Watanabe, Yan, \& Soebbing, 2015). Creative content is also important during sporting events themselves, because spectators and fans today often make use of media multitasking while following a sports match or the performance of an athlete (Weimann-Saks, Ariel, \& Elishar-Malka, 2020).

The above facts primarily present the positives of communication of sports subjects on social networks, however, Waters et al. (2011) remind us of the limited control over content on the profiles of sports organisations and the insufficient provability of return on investment. They therefore point all the more to the need for administration of profiles on social networks, especially if they have as many followers as soccer clubs and individual soccer players do (Waters et al., 2011).

\section{Social networks in the marketing communication of soccer players}

Just like sporting entities in general, individual athletes (for the purpose of this study soccer players) use social networks as a platform for communication, media ownership and content, their own publicity (marketing communication) and their own brand building (Gibbs, O'Reilly, \& Brunette, 2014). But they also add a behind-thescenes look at their professional and personal lives (Gibbs, O'Reilly, \& Brunette, 2014; Caslavova \& Voracek, 2019; Voracek, 2019). Direct individual communication between players and fans via social networks facilitates a greater connection between fans and the whole team, for which the particular soccer player plays, thereby creating closer and more connected interactive communication between players, fans and teams (Watanabe, Yan, \& Soebbing, 2016; Williams \& Chinn, 2010; Gibbs, O’Reilly, \& Brunette, 2014). Teams which then buy individual players have the opportunity to obtain and expand their own fan base online, representing a significant opportunity for team managers (Vale \& Fernandes, 2018). Fans also function as a means of support and defence of athletes and by extension also their teams against unauthorised communication attacks from other parties, whether they are from the media, the general public, or fans of other players and teams (Sanderson, 2013). Mutual interaction and communication is thus referred to as the core of the relationship between fans (followers) and an athlete on social networks (Witkemper, Lim, \& Waldburger, 2012).

Fans (followers) on social networks can ultimately have such power that they become part of an athlete's decision-making process regarding which team they should join or play for. This has been shown, for example, in a study of Chris Bosh, a basketball player in the NBA (Sanderson, 2013). Bosh and the agency representing him let his followers on Twitter vote for which team he should move to from the Toronto Raptors for the 2010/2011 season (Sanderson, 2013).

Of course, mutual communicative relationships require the creation of high-quality content, as has already been stated (Watanabe, Yan, \& Soebbing, 2015). In sport, 
especially for professional sports teams and individuals, particular attention must be paid to the authenticity and scope of engagement, as these are very important aspects for communicating on social networks (Pronschinske, Groza, \& Walker, 2012). Immediacy and exclusivity of information and content have also proved to be important factors, particularly, for example, for women's soccer players (Coche, 2014), though this can also apply to men's players. Each social network is suited to a different kind of content or, as the case may be, fans use each of them for a different purpose and need for information, as stated by Lock (2019). Facebook, for example, focuses more on support from fans, Instagram is aimed more at fun, and Twitter is a centre for up-to-date information (Lock, 2019; Gibbs, O'Reilly, \& Brunette, 2014). Information and entertainment appear to be important factors for motivating followers on the social network pages of individual athletes (Witkemper, Lim, \& Waldburger, 2012).

\section{Social networks and the market value of soccer players}

Herm, Callsen-Bracker, \& Kreis (2014, p. 484) define the market value of a professional athlete, such as a soccer player, as "an estimate of the amount of money a club would be willing to pay in order to make this athlete sign a contract, independent of an actual transaction." Therefore, even though the actual final transfer fee may be different (Moreno-Jiménez \& Zaragoza, 2011; Herm, Callsen-Bracker, \& Kreis, 2014; Müller, Simons, \& Weinmann, 2017), market value is a relevant variable for the conducted study, because it remains a basic monetary value for subsequent transfer negotiations for both the selling and buying club (Müller, Simons, \& Weinmann, 2017).

Numerous studies and authors have dealt with the influence of various factors on the final market value of soccer players (Majewski, 2016; Kologlu, et al., 2018; Aregall Abadias, 2016; Moreno-Jiménez \& Zaragoza, 2011; Müller, Simons, \& Weinmann, 2017; Singh \& Lamba, 2019; He, Cachucho, \& Knobbe, 2015; Bolgova, et al., 2018; Richau, Follert, \& Emrich, 2010; Kiefer, 2012; Herm, Callsen-Bracker, \& Kreis, 2014; Goff, Kim, \& Wilson, 2017; Kanyinda, Bouteiller, \& Karyotis, 2012). According to Majewski (2016), the factors that most influence a soccer player's market value are total goals and "assists", the value of the club that the player plays for, and the player's goodwill and "brand". Goodwill and brand can be significantly influenced by the activity and communication of players on social networks (Gibbs, O'Reilly, \& Brunette, 2014). Aregall Abadias (2016) shows the significant influence of social networks on the market value of soccer players (specifically, a $1 \%$ increase in followers on Facebook means an increase in market value of $€ 3,567,000$, while a $1 \%$ increase in followers on Twitter equals an increase in market value of $€ 3,109,000)$. Conversely, Moreno-Jiménez \& Zaragoza (2011) state that the influence of external relationships (which include fans and the mass media) on market value and on transfer fees is not particularly significant (specifically carrying a weight of 1.3\%). Müller, Simons, \& Weinmann (2017) also present a summary of the many factors that have an influence on the market value of soccer players, among them internet popularity, which also makes use of social media (specifically Facebook, Reddit and YouTube). Their effect on market value, however, is minimal (Müller, Simons, \& Weinmann, 2017). A soccer player's overall popularity, image and brand can also be referred to as "extra-soccer qualities", which undoubtedly have a major or minor influence on market value (Kanyinda, Bouteiller, \& Karyotis, 2012). Bolgova, et al. (2018) even point out the indirect influence of 
physical attractiveness on player transfers, and thus on the players' market value. On the other hand, a soccer player's current market value can also manifest itself in his image and his ability to attract crowds, because of his personality and the original and even exotic way in which he dresses or sports more or less fashionable hair styles (Kanyinda, Bouteiller, \& Karyotis, 2012). This can then mean additional income for the club generated by merchandising (Kanyinda, Bouteiller, \& Karyotis, 2012). Social networks and media in general are suitable tools which both soccer clubs and individual players use to propagate such "extra-soccer qualities", not only on the local but also on the global market (Rowe \& Gilmour, 2010; Wagg, 2007; Sondaal, 2013). The number of followers on such social media is considered to be one of the most important KPIs in the soccer industry for social media marketing (Podobnik, 2013).

\section{RESEARCH OBJECTIVES}

The main objective of the study is to research the inclusion of the social network TikTok, as the currently fastest growing form of social media, in the context of the marketing attractiveness and potential of soccer players in terms of communication range through social networks.

The TikTok social network currently appeals primarily to the younger generation of soccer fans and recipients of communications from the world's most popular soccer players. It has already taken its place among large social media, which primarily include Facebook, Twitter and Instagram. Today, these social media form a basic communication framework for direct communication between soccer players and their fans from all over the world. The main aim of the work concentrates the following partial research objectives (RO's):

RO1: an analysis of the market efficiency of soccer players from the point of view of the market value of followers for individual players on individual social networks (Facebook, Twitter, Instagram and TikTok)

RO2: an analysis of the market efficiency of soccer players from the point of view of the market value of followers for individual players on the overall communication range of profiles on social networks

RO3: an estimate of the market potential of TikTok in the context of the communication range of soccer players on social networks

\section{METHODS}

\section{Participants/Research sample}

The basic research sample chosen for the research is the top 100 soccer players according to their current market value (as per the website Transfermarkt.com) as of 18 March 2020. The top 100 soccer players have also been chosen because they have the greatest communication range via social networks and they use (with just a few exceptions) all three of the most widespread networks - Facebook, Twitter and Instagram - at the same time. The research therefore counts a total of 100 observations, or 100 observed subjects $(\mathrm{N}=100)$, whose current market value ranges from $€ 200$ million (maximal MV - Kylian Mbappé) to €50 million (minimal MV - Nicoló Zaniolo). 


\section{Procedure}

The first stage of the study consists in monitoring the official profiles of all 100 soccer players on selected social networks - Facebook (FB), Twitter (TW), Instagram (IG) and TikTok (TT). Important figures for the collection of data are the number of followers of each soccer player and the subsequent sum of figures from individual networks as the so-called Social Network Reach (hereinafter referred to as "SN reach") - all data as of 18 March 2020.

The second stage then calculates the market efficiency of soccer players from the point of view of the market value of followers for individual players on individual social networks (Facebook, Twitter, Instagram and TikTok) and on the total SN reach. This calculation is always performed by computing the ratio between the player's market value and the number of followers. It is thus possible to obtain an interesting overview of the potential attractiveness and, above all, the potential effectiveness of funds spent on the purchase of a player (here expressed as the market value) for gaining more fans for a soccer club through the social network profiles of soccer players. In addition to the resulting individual values, the values of the basic statistical description for the entire research sample are calculated here (mean, valid mean, median and standard deviation).

The third stage focuses on an estimate of the market potential of TikTok in the context of the communication range of soccer players on social networks. Market potential is estimated on the basis of existing figures of followers and users on social networks in 2020 (specifically from the most up-to-date data from Statista.com and the individual profiles of soccer players as of 18 March 2020). As a benchmark value for the estimate, the study uses the soccer player with the greatest number of followers on Facebook, Twitter and Instagram and who, at the same time, shows the greatest market efficiency from the perspective of the market value of followers. In this case, it is Cristiano Ronaldo (for values see Results). The number of followers that he has achieved are related (by ratio) to the total number of users of individual social networks (Facebook, Twitter and Instagram), the sum of the users of the three mentioned networks (modified SN reach) and the total number of unique social network users. The current number of TikTok users is multiplied by the obtained penetration indices (referred to in the study as the $C R$ indices). This creates a battery of five numerical (number of followers) estimates, from which the mean potential (including the average CR index) is then determined. The $C R$ indices are also interpreted as the potential penetration of TikTok in the case of the expected and forecasted growth (and thus changes) in the number of users (Omnicore. com, 2020; Datareportal: Digital 2020, 2020; Socialbakers.com, 2020).

\section{RESULTS}

\section{(R01, R02) Market efficiency of soccer players in terms of the market value of followers on social networks}

The overall main results of the market efficiency of soccer players in terms of market values of followers on social networks are clearly specified and presented in Appendix 1. The overall results are supplemented by Appendix 2, in which a logarithmic scale is again used for the $y$-axis because of the possibility of displaying significantly different values. Market efficiency is only calculated here for the valid research sample for individual social networks, so only valid descriptive statistics are presented. 
The overall results indicate the dominance of Instagram (similarly to the number of followers) even in terms of market efficiency of communication on social networks, where the hypothetical costs (for a potential buyer from a club) for gaining another follower are Valid $M=€ 535.73$. The standard deviation for Instagram is also the lowest (Valid $S D=€ 4,722.10$ ) among the individual networks. Instagram surpasses the other social networks even more noticeably in median value (Valid Med $=€ 26.04$ ). It can therefore be noted that the hypothetical costs (for a potential buyer from a club) for gaining another follower on Instagram are equal to or lower than $€ 26.04$ for $50 \%$ of soccer players (from the studied top 100 players according to market value). A significant point of interest is the clear similarity of Instagram results to the efficiency of the overall $\mathrm{SN}$ reach (Valid $M=€ 500.07$, Valid $S D=€ 4,526.74$ and Valid Med $=€ 20.35$ ). From this perspective, Instagram is the most important of all four studied social networks.

Other social networks in terms of the researched and measured efficiency lag behind Instagram and, as a consequence, also the overall SN reach. Facebook lags behind the least (Valid $M=€ 1,469.94$, Valid $S D=€ 5,653.46$ and Valid Med $=€ 154.72$ ). It is followed by Twitter (Valid $M=€ 28,559.15$, Valid $S D=€ 173,950.53$ and Valid Med $=€ 134.23$ ), albeit with a lower and therefore more efficient median than Facebook. TikTok so far appears to be a highly inefficient communication network (Valid $M=€ 3,132,639.05$, Valid $S D=€ 6,899,395.12$ and Valid Med $=€ 22,102.94)$, however the thus far low use of the network by the top 100 soccer players (Valid $N=25$ ) must be taken into account.

An interesting comparison is also provided in Appendix 1 when looking at the results of individual players. The current relatively low market value of Cristiano Ronaldo $(M V=€ 75,000,000$, which is his lowest since 7 January 2010 according to Transfermarkt.com) further increased the market efficiency of the communication range with a total $S N$ value of $€ 0.18$. In addition to TikTok (TT value $=€ 386.00$ ), the hypothetical cost (for a potential buyer from a club) for gaining another follower through C. Ronaldo (as the only one of the top 100 surveyed) on all social networks is less than $€ 1.00$ (FB value $=€ 0.60, T W$ value $=€ 0.90$, and $I G$ value $=€ 0.36)$. Cristiano Ronaldo and his attained values (both communication range and market efficiency of communication on social networks) can therefore be seen as a benchmark for a subsequent estimate and calculation of the market potential of TikTok in the context of the communication range of soccer players on social networks.

In contrast, Rodri (Manchester City) has a relatively high market value for his age (age $=23$, a young player with good prospects) $M V=€ 80,000,000$ (even higher than C. Ronaldo), but his total SN reach is only 1,757 people (followers on social networks). In terms of communication range on social networks, this means hypothetical costs for Manchester City with a total SN value of $€ 45,532.16$ per follower. In comparison with the total SN value of other soccer players, Rodri is highly inefficient among the research sample, with orders of magnitude worse than other players in the sample (the second worst efficiency is shown by Mikel Oyarzabal of Real Sociedad with a total $S N$ value of $€ 748.13)$. It is important to note, however, that both players (Rodri and Mikel Oyarzabal) only use two of the four social networks for communication, Twitter and Instagram. In the case of Rodri, it is therefore clear that his market value $(M V=€ 80,000,000$ - currently ranking him as the 32 nd best player in terms of market value) reflects entirely different aspects of the player (e.g., performance in the 
game) to a much greater extent than marketing and communication attractiveness. Even so, this result can be viewed positively from the perspective of significant future marketing and communication potential, which could be significantly influenced by his currently high market value.

\section{(R03) Estimate of the market potential of TikTok in the context of the communication range of soccer players on social networks}

The results of the calculation of an estimate of the market value of TikTok in terms of the communication range of soccer players on social networks is presented in Appendix 3. For comparison, Appendix 3 also presents the current greatest communication range on TikTok from the ranks of soccer players, specifically Mohamed Salah ( TT followers $=530,700)$, Alphonso Davies $($ TT followers $=427,200)$ and Cristiano Ronaldo ( TT followers $=194,300)$.

The estimated market potential of number of followers of soccer players on TikTok has multiple variants, depending on which social network or what number of users the estimate is based on. An estimate (index and number of followers) calculated on the basis of Instagram can particularly be considered to produce important and relevant values. Current statistics on TikTok users are very similar to the other studied social networks in terms of age and gender of users (Omnicore.com, 2020; Datareportal: Digital 2020, 2020; Statista.com, 2020). However, the relevance of an estimate based on Instagram is based on the form and style of posts (TikTok - 15s videos, Instagram - Insta Stories short videos), the largest average use of Instagram (and number of followers) for soccer players, and the fact that according to the study Datareportal: Digital 2020 (2020), up to 500 million people watch short videos on Instagram on at least a monthly basis.

The estimated potential number of followers of soccer players on TikTok is therefore $166,400,000$, while the average estimate from the studied social networks is $115,796,545$ followers. Of course, attaining these values will only be realistic for exceptionally popular soccer players of the future, following the example of contemporary players C. Ronaldo, L. Messi, or Neymar Jr. However, a more important figure than the estimate of the absolute number of followers, which can be found in Appendix 3 , is the so-called CR index, which expresses the ratio of the number of followers of C. Ronaldo (the chosen benchmark for estimating potential) to the number of users on the social network. This index is then applicable for the future development (increase/ decrease) of the number of users of the selected social networks, including TikTok. An estimate based on Instagram attains a CR index of 0.208 (20.8\%). An estimate based on the studied social networks produces an average CR index of 0.14475 (14.475\%). For the top 100 soccer players (according to market value), the estimated market potential (number of followers) of TikTok is therefore up to 14.5-21\% (115.8-166.4 million in 2020 ) from the total number of TikTok users (800 million in 2020).

\section{DISCUSSION AND IMPLICATIONS}

This study presents the currently fastest growing social network, TikTok (Omnicore. com, 2020; Datareportal: Digital 2020, 2020; Socialbakers.com, 2020; Statista.com, 2020 ), in the overall context of the communication range of soccer players on social networks. The social networks that form the overall context for this study are Face- 
book, Twitter and Instagram, which are currently the most popular and most widely used by athletes (Mogale, 2020; Yoon, Petrick, \& Backman, 2017) and especially by soccer players. For this reason, the study does not cover other social media such as YouTube, Reddit and Pinterest, which some athletes and sports clubs also use for their marketing communications. In addition, each social network is suited to and used for different kinds of content (Lock, 2019; Gibbs, O’Reilly, \& Brunette, 2014). The soccer players who have been selected for the study are currently in the top 100 by market value according to the Transfermarkt.com website. The use of market values from Transfermarkt.com is justified by the fact that Transfermarkt.com is "the leading website on the soccer transfer market" according to Müller, Simons, \& Weinmann (2017, p. 612). "The site offers general soccer-related data, such as scores and results, soccer news, transfer rumours, and estimations of market value at the individual and team levels for most professional soccer leagues." The results of the study show that not all soccer players in the top 100 (according to market value) use all three of the currently most widely used social networks. Based on this fact, we have derived so-called valid quantities, which only include those players who have their own official profile on a particular social network. For different networks, $N$ therefore varies - for Facebook $N=96$, for Twitter $N=94$, and for Instagram $N=98$. Despite the currently high number of TikTok users, which is around 800 million (Omnicore.com, 2020; Datareportal: Digital 2020, 2020; Socialbakers.com, 2020; Statista.com, 2020), very few players from the research sample have their own official profile, $N=25$. TikTok is not yet at the centre of attention of soccer players as much as other networks.

One of the significant benefits of the study is an evaluation of the market efficiency of soccer players in terms of the market value of followers on social networks. For each of the top 100 soccer players (according to market value on Transfermarkt.com), the ratio between market value and the number of followers is calculated. This provides soccer clubs with an overview of the attractiveness of a player in terms of communication range, which a potential buying club also pays for (in addition to the player himself and his performance in the game) when purchasing a player. It is therefore another aspect that a player brings to a club. Attractiveness (Kanyinda, Bouteiller, \& Karyotis, 2012), image (Anagnostopoulos, Parganas, Chadwick, \& Fenton, 2018; Kanyinda, Bouteiller, \& Karyotis, 2012), connection with fans (Watanabe, Yan, \& Soebbing, 2016; Williams \& Chinn, 2010; Gibbs, O'Reilly, \& Brunette, 2014), fan base (Vale \& Fernandes, 2018), support and defence (Sanderson, 2013), opinion leadership (Araujo, 2019), global reach (Rowe \& Gilmour, 2010; Wagg, 2007; Sondaal, 2013), sufficient external sources of funding via sponsoring and sales of television rights (Pieters, Knoben, \& Pouwels, 2012), and loyal fans (Yoon, Petrick, \& Backman, 2017) are all aspects which create so-called "extra-soccer qualities" (Kanyinda, Bouteiller, \& Karyotis, 2012) which a soccer player brings to the club that purchases him for a certain monetary value. This can then mean additional income for the club generated by merchandising (Kanyinda, Bouteiller, \& Karyotis, 2012). All of the mentioned "extra-soccer qualities" reflect the communication range (number of followers) of a soccer player on social networks; the higher the number of followers and the lower the market value, the cheaper and more attractive a soccer player is in this regard for a buying club. That is why the ratio between market value and number of followers has been chosen. The purchasing club therefore at least gains a rough idea of the efficiency 
of investments, thereby partially reducing the disadvantage mentioned by Waters, et al. (2011) on the insufficient provability of return on investment into communication via social networks. In addition, followers on social networks can have the power to influence the resulting transfer fee through their own opinion on the choice of the club that a player is going to play for, as Sanderson (2013) shows.

A discussion about the choice of the variable "market value" is then well motivated, because in the end market value (on Transfermarkt.com) is not the price a soccer player is actually bought for. It would therefore be more appropriate to choose the transfer fee, as used by Moreno-Jiménez \& Zaragoza (2011). As is shown in the theoretical background, however, (Moreno-Jiménez \& Zaragoza, 2011; Herm, Callsen-Bracker, \& Kreis, 2014; Müller, Simons, \& Weinmann, 2017) market value is a basic monetary value for subsequent transfer negotiations. Müller, Simons, \& Weinmann (2017, p. 611) also state that "Market values can be understood as estimates of transfer fees - that is, prices that could be paid for a player on the soccer market - so they play an important role in transfer negotiations." In view of the time that this study has been conducted (during the COVID-19 pandemic) and the termination or suspension of soccer competitions, the current market values (listed on Transfermarkt.com) are a more than relevant estimate of players' current values. That is one reason why they have been used in the study, even though they may ultimately be different to transfer fees, which will only become relevant after the restart of soccer competitions and the transfer market.

In terms of achieved results, Instagram is again the most effective social network for communication, where every follower costs on average Valid $M=€ 535.73$, which is very similar to the average efficiency of the total SN reach, where Valid $M=€ 500.07$. Among soccer players, the most efficient is Cristiano Ronaldo with the values $F B$ value $=€ 0.60, T W$ value $=€ 0.90, I G$ value $=€ 0.36, T T$ value $=€ 386.00$, and Total $S N$ value $=€ 0.18$. His efficiency and total attained number of followers then represent the chosen benchmark for estimating the market potential of TikTok.

An estimate of the market potential of TikTok in the context of the communication range of soccer players on social networks has been calculated using the currently attained number of followers (of Cristiano Ronaldo) and users of individual networks, as well as the total number of unique users of all social media according to figures from Statista.com (January 2020) - see Appendix 3. The study thus brings another aspect for TikTok in the overall context of social network profiles of soccer players. TikTok (in a similar way to Instagram) has mostly a younger group of users (in terms of age), and it is therefore possible to consider the impact of communication by soccer players on young fans, with whom it is then possible to build a strong relationship and love for a brand, as Vale \& Fernandes (2018) say. However, for soccer players and/or their marketing agency or manager representation, an additional social network means more work (Waters, et al., 2011), activities, effort and time (Waters, et al., 2011), because communication should be creative (Watanabe, Yan, \& Soebbing, 2015), authentic (Pronschinske, Groza, \& Walker, 2012), immediate (Coche, 2014; Witkemper, Lim, \& Waldburger, 2012) and with a high quantity of engagement (Pronschinske, Groza, \& Walker, 2012). It thereby places demands on systematic and strategic activities regarding the planning and implementation of communication on another social network like TikTok (Watanabe, Yan, \& Soebbing, 2016). 
TikTok is a network based primarily on sharing original content by way of short videos with a wide range of editing and creative options (TikTok, 2020). For soccer players, such short videos are a very attractive form of communication with fans. Particularly at times of an unexpected large-scale event such as the COVID-19 pandemic (when the study was conducted), TikTok provides a possibility to present creative content from the privacy of the players' own homes, a fact which is supported by the authors Watanabe, Yan, \& Soebbing (2015), Gibbs, O’Reilly, \& Brunette (2014), Čáslavová \& Voráček (2019) and Voráček (2019). Short videos are also suitable for authenticity and a high level of engagement (Pronschinske, Groza, \& Walker, 2012). The ease and speed with which videos can be edited meets the requirement for immediacy, exclusivity and rapidity of the content of communications (Coche, 2014; Witkemper, Lim, \& Waldburger, 2012).

Given the characteristics of TikTok, the study uses Cristiano Ronaldo (as a benchmark) and Instagram for the resulting relevant estimate of the market potential of soccer players' communication range. Instagram is indeed the most widely used network by soccer players, as the results of this study show. In addition, its content is particularly oriented towards entertainment (Lock, 2019; Gibbs, O’Reilly, \& Brunette, 2014), which proves to be an especially important factor for motivating followers on the social network profiles of individual athletes (Witkemper, Lim, \& Waldburger, 2012). The resulting relevant estimate of TikTok's market potential in the context of the communication range of soccer players on social networks is up to $14.5-21 \%$ of followers (115.8-166.4 million in 2020) from the total number of TikTok users (800 million in 2020). At present, the penetration of soccer players with the largest number of followers on TikTok is only $0.066 \%$ (530,700 followers) of the total number of users ( 800 million). There is therefore a great, as yet unfulfilled and unused future potential for the growth of communication on this social network.

\section{Limitations and future research}

The presented study naturally has certain restrictions and limitations. One of the most important restrictions is the already mentioned use of market values in spite of the fact that the resulting value at which a soccer player is traded between teams is different and depends on individual negotiations of the soccer clubs involved (Moreno-Jiménez \& Zaragoza, 2011; Herm, Callsen-Bracker, \& Kreis, 2014; Müller, Simons, \& Weinmann, 2017). The study is then further limited to the use of Facebook, Twitter and Instagram, although both soccer clubs and players themselves use other social media, such as YouTube, Reddit and Pinterest. However, these other networks are not as widespread and widely used as Facebook, Twitter and Instagram (Statista.com, 2020). The study includes only the top 100 soccer players according to their current market value (on Transfermarkt.com), which excludes even players of such popularity (in terms of communication range and brand image or brand awareness) as Daniel Carvajal, Isco, Jordi Alba, David de Gea, Georginio Wijnaldum, Mateo Kovačić, Karim Benzema, Gareth Bale, Luis Suárez, and others. The last limitation is the performance of static analyses that do not reflect the dynamic development over time in recent years. If this was taken into account, an even more sophisticated and accurate estimate of the market potential of TikTok could be made.

The above-mentioned limitations are an opportunity for further future research dealing with the market efficiency of social networks not only of soccer players, but 
also of individual athletes in other sports branches or entire sports clubs. That being said, the social network TikTok as a whole provides a primary stimulus for future research. Not only is it the currently fastest growing social network in terms of user numbers (Omnicore.com, 2020; Datareportal: Digital 2020, 2020; Socialbakers.com, 2020; Statista.com, 2020), but it is also a thus far rather unexplored network in sport and in many other possible areas in general.

\section{CONCLUSION}

The study puts the TikTok social network, as the currently fastest growing form of social media, into the context of marketing attractiveness and potential of soccer players in terms of communication range through social networks. According to the ascertained results, TikTok is currently a minimally used social network among soccer players. The largest number of followers is only 530,700 (Mohamed Salah), while on Facebook it is 126,023,622 (Cristiano Ronaldo), on Twitter 83,100,000 (also C. Ronaldo), and on Instagram 208,000,000 (again C. Ronaldo). On the other hand, there is all the more space for producing something new, attractive and creative, and for taking advantage of potential such as that offered by TikTok. All of this is demonstrated by the ascertained market efficiency values of followers of individual players. The conclusion is a final estimate of the market potential of TikTok in the context of the communication range of soccer players on social networks. According to the method used to calculate this estimate, followers range from $14.5-21 \%$ (115.8-166.4 million in 2020) of the total number of TikTok users.

\section{ACKNOWLEDGEMENTS}

This work was supported by the scientific branch development program PROGRESS [Q19] at the Charles University in Prague.

\section{REFERENCES}

Anagnostopoulos, C., Parganas, P., Chadwick, S., \& Fenton, A. (2018). Branding in pictures: using Instagram as a brand management tool in professional team sport organisations. European Sport Management Quarterly, 18(4), 413-438.

Araujo, T. (2019). The impact of sharing brand messages: How message, sender and receiver characteristics influence brand attitudes and information diffusion on Social Networking Sites. Communications, 44(2), 162-184.

Aregall Abadias, Ò. (2016). Econometric model for the valuation of football players.

BiggestGlobalSports.com: A statistics-based analysis of the world's most popular sports (2020). Retrieved from http://www.biggestglobalsports.com.

Bolgova, V., Vinopal, M., Nikitina, N., \& Pustokhina, T. (2018). Pretty is as pretty plays: the influence of physical attractiveness on the transfer value of football players. Available at SSRN 3203312.

Datareportal: Digital 2020 - global digital overview (2020). Retrieved from https:// datareportal.com/reports/digital-2020-global-digital-overview.

Caslavova, E., \& Voracek, J. (2019). Marketing Trends in Social Networking Sites Usage in Sport. International Journal of Sport Communication, 3(4), 396-400. UT-WOS: 000467818300003.

Coche, R. (2014). What women's soccer fans want: A Twitter study. Soccer \& Society, 15(4), 449-471. 
Gibbs, C., O’Reilly, N., \& Brunette, M. (2014). Professional team sport and Twitter: Gratifications sought and obtained by followers. International Journal of Sport Communication, 7(2), 188-213.

Goff, B. L., Kim, H. Y., \& Wilson, D. P. (2017). Estimating the market value of collegiate football players from professional factor shares. Applied Economics Letters, 24(4), 233-237.

Hambrick, M. E., Simmons, J. M., Greenhalgh, G. P., \& Greenwell, T. C. (2010). Understanding professional athletes' use of Twitter: A content analysis of athlete tweets. International Journal of Sport Communication, 3(4), 454-471.

He, M., Cachucho, R., \& Knobbe, A. J. (2015). Football Player's Performance and Market Value. In: MLSA@PKDD/ECML (pp.87-95).

Herm, S., Callsen-Bracker, H. M., \& Kreis, H. (2014). When the crowd evaluates soccer players' market values: Accuracy and evaluation attributes of an online community. Sport Management Review, 17(4), 484-492.

Kanyinda, A., Bouteiller, C., \& Karyotis, C. (2012). Human capital: assessing the financial value of football players on the basis of real options theory. Investment management and financial innovations, (9, Iss. 4), 27-37.

Kiefer, S. (2012). The impact of the Euro 2012 on popularity and market value of football players (No. 11/2012). Diskussionspapier des Instituts für Organisationsökonomik.

Kologlu, Y., Birinci, H., Kanalmaz, S. I., \& Ozyilmaz, B. (2018). A Multiple Linear Regression Approach For Estimating the Market Value of Football Players in Forward Position. arXiv preprint arXiv:1807.01104.

Li, Z., \& Huang, K. W. (2015). The monetary value of twitter followers: Evidences from NBA players.

Lock, L. B. (2019). Join Our Team: How sports organizations satisfy the needs of sports fans on Twitter. 2019 NCUR.

Majewski, S. (2016). Identification of factors determining market value of the most valuable football players. Journal of Management and Business Administration. Central Europe, 24(3), 91-104.

Mogale, S. U. (2020). A study on impact of Social Media on adolescent and youth. Studies in Indian Place Names, 40(42), 80-87.

Moreno-Jiménez, J. M., \& Zaragoza, G. D. M. (2011). An AHP/ANP multicriteria methodology to estimate the value and transfers fees of professional football players. Proceedings ISAHP 2011.

Müller, O., Simons, A., \& Weinmann, M. (2017). Beyond crowd judgments: Data-driven estimation of market value in association football. European Journal of Operational Research, 263(2), 611-624. doi: http://dx.doi.org/10.1016/j.ejor.2017.05.005.

Omnicore.com: TikTok by the Numbers - Stats, Demographics \& Fun Facts (2020). Retrieved from https://www.omnicoreagency.com/tiktok-statistics.

Özsoy, S. (2011). Use of new media by Turkish fans in sport communication: Facebook and Twitter. Journal of Human Kinetics, 28, 165-176.

Pérez, L. (2013). What drives the number of new Twitter followers? An economic note and a case study of professional soccer teams. Economics Bulletin, 33(3), 1941-1947.

Pieters, M., Knoben, J., \& Pouwels, M. (2012). A social network perspective on sport management: The effect of network embeddedness on the commercial performance of sport organizations. Journal of Sport Management, 26(5), 433-444.

Podobnik, V. (2013). An analysis of facebook social media marketing key performance indicators: The case of premier league brands. In: Proceedings of the 12th International Conference on Telecommunications (pp. 131-138). IEEE.

Pronschinske, M., Groza, M. D., \& Walker, M. (2012). Attracting Facebook'fans': The importance of authenticity and engagement as a social networking strategy for professional sport teams. Sport Marketing Quarterly, 21(4), 221. 
Richau, L., Follert, F., \& Emrich, M. F. (2010). Performance indicators in football: The im-portance of actual performance for the market value of football players. Sonderausgabe zur 23. Jahrestagung des Arbeitskreises Sportökonomie 2019, 41.

Rowe, D., \& Gilmour, C. (2010). Sport, media, and consumption in Asia: A merchandised milieu. American Behavioral Scientist, 53(10), 1530-1548.

Sanderson, J. (2013). From loving the hero to despising the villain: Sports fans, Facebook, and social identity threats. Mass Communication and Society, 16(4), 487-509.

Shoham, D. A., et al. (2012). An actor-based model of social network influence on adolescent body size, screen time, and playing sports. PloS one, 7(6). doi: 10.1371/journal.pone.0039795.

Singh, P., \& Lamba, P. S. (2019). Influence of crowdsourcing, popularity and previous year statistics in market value estimation of football players. Journal of Discrete Mathematical Sciences and Cryptography, 22(2), 113-126.

Socialbakers.com (2020). Retrieved from https://www.socialbakers.com.

Sondaal, T. (2013). Football's grobalization or globalization? The lessons of Liverpool Football Club's evolution in the Premier League era. Soccer \& Society, 14(4), 485-501.

Statista.com (2020). Retrieved from https://www.statista.com.

Tiago, T., Tiago, F., Faria, S. D., \& Couto, J. P. (2016). Who is the better player? Off-field battle on Facebook and Twitter. Business Horizons, 59(2), 175-183.

TikTok (2020). Retrieved from https://www.tiktok.com/home.

TotalSportek.com: 25 World's Most Popular Sports (Ranked by 13 factors) (2020). Retrieved from https://www.totalsportek.com/most-popular-sports.

Transfermarkt.com (2020). Retrieved from https://www.transfermarkt.com.

Vale, L., \& Fernandes, T. (2018). Social media and sports: driving fan engagement with football clubs on Facebook. Journal of strategic marketing, 26(1), 37-55.

Voracek, J. (2019). Trends and Tools in Marketing Communication in Today's Sport. In: Proceedings of the Marketing Identity 2019: Offline Is the New Online (pp. 390-400). UCM Trnava.

Wagg, S. (2007). Angels of us all? Football management, globalization and the politics of celebrity. Soccer \& Society, 8(4), 440-458.

Watanabe, N. M., Yan, G., \& Soebbing, B. P. (2016). Consumer interest in major league baseball: An analytical modeling of Twitter. Journal of Sport Management, 30(2), 207-220.

Watanabe, N., Yan, G., \& Soebbing, B. P. (2015). Major League Baseball and Twitter usage: The economics of social media use. Journal of Sport Management, 29(6), 619-632.

Waters, R. D., Burke, K. A., Jackson, Z. H., \& Buning, J. D. (2011). Using stewardship to cultivate fandom online: Comparing how National Football League teams use their web sites and Facebook to engage their fans. International Journal of Sport Communication, 4(2), 163-177.

Weimann-Saks, D., Ariel, Y., \& Elishar-Malka, V. (2020). Social Second Screen: WhatsApp and Watching the World Cup. Communication \& Sport, 8(1), 123-141.

Williams, J., \& Chinn, S. J. (2010). Meeting relationship-marketing goals through social media: A conceptual model for sport marketers. International Journal of Sport Communication, 3(4), 422-437. doi: https://doi.org/10.1123/ijsc.3.4.422.

Witkemper, C., Lim, C. H., \& Waldburger, A. (2012). Social media and sports marketing: Examining the motivations and constraints of Twitter users. Sport Marketing Quarterly, 21(3), 170-183.

WorldAtlas.com: The Most Popular Sports in the World (2020). Retrieved from https://www .worldatlas.com/articles/what-are-the-most-popular-sports-in-the-world.html.

Yoon, S., Petrick, J. F., \& Backman, S. J. (2017). Twitter power and sport-fan loyalty: The moderating effects of Twitter. International Journal of Sport Communication, 10(2), 153-177.

Zagnoli, P., \& Radicchi, E. (2010). The football fan community as a determinant stakeholder in value co-creation. Physical Culture and Sport. Studies and Research, 50(1), 79-99. 


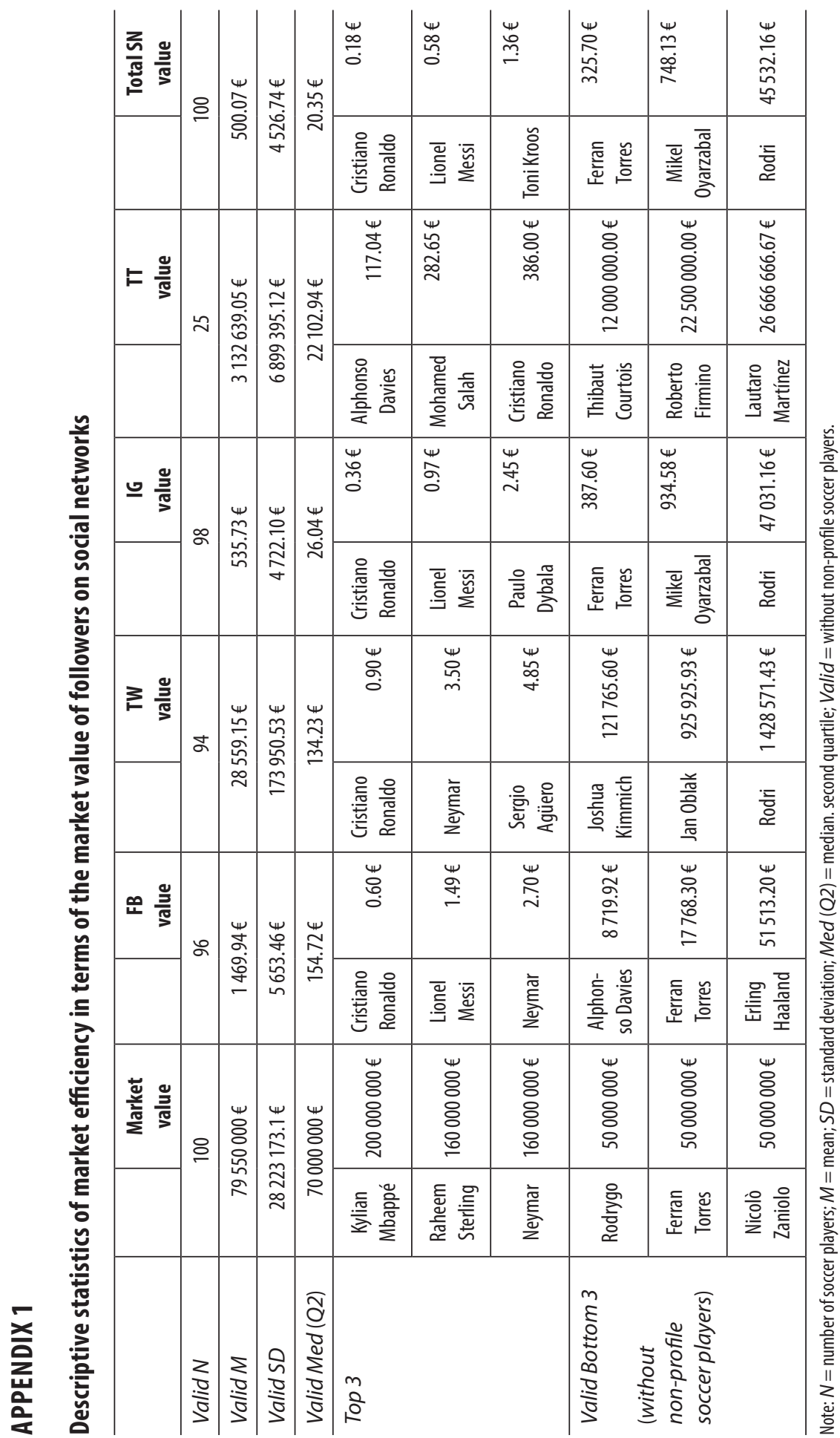




\section{APPENDIX 2}

Descriptive statistics of market efficiency in terms of the market value of followers on social networks

\begin{tabular}{|c|c|c|c|c|c|c|}
\hline $\begin{array}{c}\text { Market } \\
\text { value rank }\end{array}$ & Player & Market value & Age & Club & FB followers & FB value \\
\hline 1 & Kylian Mbappé & $200000000 €$ & 21 & Paris Saint-Germain & 2526784 & $79,15 €$ \\
\hline 2 & Raheem Sterling & $160000000 €$ & 25 & Manchester City & 2318995 & $69,00 €$ \\
\hline 3 & Neymar & $160000000 €$ & 28 & Paris Saint-Germain & 59364955 & $2,70 €$ \\
\hline 4 & Sadio Mané & $150000000 €$ & 27 & Liverpool FC & 1256243 & $119,40 €$ \\
\hline 5 & Mohamed Salah & $150000000 €$ & 27 & Liverpool FC & 12651322 & $11,86 €$ \\
\hline 6 & Harry Kane & $150000000 €$ & 26 & Tottenham Hotspur & 1958259 & $76,60 €$ \\
\hline 7 & Kevin De Bruyne & $150000000 €$ & 28 & Manchester City & 3475017 & $43,17 €$ \\
\hline 8 & Lionel Messi & $140000000 €$ & 32 & FC Barcelona & 93675335 & $1,49 €$ \\
\hline 9 & Jadon Sancho & $130000000 €$ & 19 & Borussia Dortmund & 85329 & $1523,51 €$ \\
\hline 10 & Antoine Griezmann & $120000000 €$ & 28 & FC Barcelona & 10821929 & $11,09 €$ \\
\hline 11 & Trent Alexander-Arnold & $110000000 €$ & 21 & Liverpool FC & 341575 & $322,04 €$ \\
\hline 12 & Bernardo Silva & $100000000 €$ & 25 & Manchester City & 363666 & $274,98 €$ \\
\hline 13 & N'Golo Kanté & $100000000 €$ & 28 & Chelsea FC & 1130926 & $88,42 €$ \\
\hline 14 & Leroy Sané & $100000000 €$ & 24 & Manchester City & 720381 & $138,82 €$ \\
\hline 15 & Virgil van Dijk & $100000000 €$ & 28 & Liverpool FC & 453479 & $220,52 €$ \\
\hline 16 & Paul Pogba & $100000000 €$ & 27 & Manchester United & 10318977 & $9,69 €$ \\
\hline 17 & Jan Oblak & $100000000 €$ & 27 & Atlético Madrid & 52496 & $1904,91 €$ \\
\hline 18 & Eden Hazard & $100000000 €$ & 29 & Real Madrid & 10023105 & $9,98 €$ \\
\hline 19 & João Félix & $90000000 €$ & 20 & Atlético Madrid & 146538 & $614,18 €$ \\
\hline 20 & Frenkie de Jong & $90000000 €$ & 22 & FC Barcelona & 278165 & $323,55 €$ \\
\hline 21 & Kai Havertz & $90000000 €$ & 20 & Bayer 04 Leverkusen & 43294 & $2078,81 €$ \\
\hline 22 & Paulo Dybala & $90000000 €$ & 26 & Juventus FC & 7652069 & $11,76 €$ \\
\hline 23 & Serge Gnabry & $90000000 €$ & 24 & Bayern Munich & 580578 & $155,02 €$ \\
\hline 24 & Saúl Ñíguez & $90000000 €$ & 25 & Atlético Madrid & 480178 & $187,43 €$ \\
\hline 25 & Roberto Firmino & $90000000 €$ & 28 & Liverpool FC & 1240474 & $72,55 €$ \\
\hline 26 & Alisson & $90000000 €$ & 27 & Liverpool FC & 1541706 & $58,38 €$ \\
\hline 27 & Marc-André ter Stegen & $90000000 €$ & 27 & FC Barcelona & 3240389 & $27,77 €$ \\
\hline 28 & Romelu Lukaku & $85000000 €$ & 26 & Inter Milan & 2934461 & $28,97 €$ \\
\hline 29 & Christian Eriksen & $85000000 €$ & 28 & Inter Milan & 145271 & $585,11 €$ \\
\hline 30 & Erling Haaland & $80000000 €$ & 19 & Borussia Dortmund & 1553 & $51513,20 €$ \\
\hline 31 & Lautaro Martínez & $80000000 €$ & 22 & Inter Milan & 123466 & $647,95 €$ \\
\hline 32 & Rodri & $80000000 €$ & 23 & Manchester City & 0 & \\
\hline 33 & Sergej Milinkovic-Savic & $80000000 €$ & 25 & SS Lazio & 32654 & $2449,93 €$ \\
\hline
\end{tabular}




\begin{tabular}{|c|c|c|c|c|c|c|c|}
\hline TW followers & TW value & IG followers & IG value & $\begin{array}{c}\text { TikTok } \\
\text { followers }\end{array}$ & TT value & SN Reach & SN value \\
\hline 3900000 & $51,28 €$ & 39600000 & $5,05 €$ & 28500 & $7017,54 €$ & 46055284 & $4,34 €$ \\
\hline 2300000 & $69,57 €$ & 6800000 & $23,53 €$ & 0 & & 11418995 & $14,01 €$ \\
\hline 45700000 & $3,50 €$ & 2000000 & $80,00 €$ & 57900 & $2763,39 €$ & 107122855 & $1,49 €$ \\
\hline 22700 & $6607,93 €$ & 6900000 & $21,74 €$ & 0 & & 8178943 & $18,34 €$ \\
\hline 11500000 & $13,04 €$ & 37300000 & $4,02 €$ & 530700 & $282,65 €$ & 61982022 & $2,42 €$ \\
\hline 2800000 & $53,57 €$ & 9500000 & $15,79 €$ & 0 & & 14258259 & $10,52 €$ \\
\hline 2100000 & $71,43 €$ & 10400000 & $14,42 €$ & 33 & $4545454,55 €$ & 15975050 & $9,39 €$ \\
\hline 2900000 & $48,28 €$ & 145000000 & $0,97 €$ & 18500 & $7567,57 €$ & 241593835 & $0,58 €$ \\
\hline 266300 & $488,17 €$ & 3600000 & $36,11 €$ & 1868 & $69593,15 €$ & 3953497 & $32,88 €$ \\
\hline 6800000 & $17,65 €$ & 30000000 & $4,00 €$ & 4576 & $26223,78 €$ & 47626505 & $2,52 €$ \\
\hline 1100000 & $100,00 €$ & 3900000 & $28,21 €$ & 0 & & 5341575 & $20,59 €$ \\
\hline 755900 & $132,29 €$ & 2000000 & $50,00 €$ & 0 & & 3119566 & $32,06 €$ \\
\hline 891100 & $112,22 €$ & 6700000 & $14,93 €$ & 0 & & 8722026 & $11,47 €$ \\
\hline 1500000 & $66,67 €$ & 4900000 & $20,41 €$ & 176 & $568181,82 €$ & 7120557 & $14,04 €$ \\
\hline 1600000 & $62,50 €$ & 8900000 & $11,24 €$ & 0 & & 10953479 & $9,13 €$ \\
\hline 7300000 & $13,70 €$ & 39800000 & $2,51 €$ & 1617 & $61842,92 €$ & 57420594 & $1,74 €$ \\
\hline 108 & $925925,93 €$ & 1200000 & $83,33 €$ & 0 & & 1252604 & $79,83 €$ \\
\hline 6700000 & $14,93 €$ & 26800000 & $3,73 €$ & 5687 & $17583,96 €$ & 43528792 & $2,30 €$ \\
\hline 159600 & $563,91 €$ & 2900000 & $31,03 €$ & 22300 & $4035,87 €$ & 3228438 & $27,88 €$ \\
\hline 456800 & $197,02 €$ & 6500000 & $13,85 €$ & 3201 & $28116,21 €$ & 7238166 & $12,43 €$ \\
\hline 43600 & $2064,22 €$ & 633000 & $142,18 €$ & 0 & & 719894 & $125,02 €$ \\
\hline 1900000 & $47,37 €$ & 36700000 & $2,45 €$ & 15400 & $5844,16 €$ & 46267469 & $1,95 €$ \\
\hline 595500 & $151,13 €$ & 1500000 & $60,00 €$ & 0 & & 2676078 & $33,63 €$ \\
\hline 426200 & $211,17 €$ & 1200000 & $75,00 €$ & 0 & & 2106378 & $42,73 €$ \\
\hline 1626 & $55350,55 €$ & 12900000 & $6,98 €$ & 4 & $22500000,00 €$ & 14142104 & $6,36 €$ \\
\hline 928000 & $96,98 €$ & 6600000 & $13,64 €$ & 0 & & 9069706 & $9,92 €$ \\
\hline 1800000 & $50,00 €$ & 10900000 & $8,26 €$ & 48200 & $1867,22 €$ & 15988589 & $5,63 €$ \\
\hline 1900000 & $44,74 €$ & 5900000 & $14,41 €$ & 37200 & $2284,95 €$ & 10771661 & $7,89 €$ \\
\hline 729600 & $116,50 €$ & 2000000 & $42,50 €$ & 0 & & 2874871 & $29,57 €$ \\
\hline 221700 & $360,85 €$ & 3500000 & $22,86 €$ & 0 & & 3723253 & $21,49 €$ \\
\hline 0 & & 2800000 & $28,57 €$ & 3 & $26666666,67 €$ & 2923469 & $27,36 €$ \\
\hline 56 & $1428571,43 €$ & 1701 & $47031,16 €$ & 0 & & 1757 & $45532,16 €$ \\
\hline 1279 & $62548,87 €$ & 470000 & $170,21 €$ & 0 & & 503933 & $158,75 €$ \\
\hline
\end{tabular}




\begin{tabular}{|c|c|c|c|c|c|c|}
\hline $\begin{array}{c}\text { Market } \\
\text { value rank }\end{array}$ & Player & Market value & Age & Club & FB followers & FB value \\
\hline 34 & Marcus Rashford & $80000000 €$ & 22 & Manchester United & 3254096 & $24,58 €$ \\
\hline 35 & Andrew Robertson & $80000000 €$ & 26 & Liverpool FC & 235387 & $339,87 €$ \\
\hline 36 & Dele Alli & $80000000 €$ & 23 & Tottenham Hotspur & 681573 & $117,38 €$ \\
\hline 37 & Timo Werner & $80000000 €$ & 24 & RB Leipzig & 157963 & $506,45 €$ \\
\hline 38 & RaphaëlVarane & $80000000 €$ & 26 & Real Madrid & 8451352 & $9,47 €$ \\
\hline 39 & Joshua Kimmich & $80000000 €$ & 25 & Bayern Munich & 549655 & $145,55 €$ \\
\hline 40 & Heung-min Son & $80000000 €$ & 27 & Tottenham Hotspur & 1085823 & $73,68 €$ \\
\hline 41 & Casemiro & $80000000 €$ & 28 & Real Madrid & 6249420 & $12,80 €$ \\
\hline 42 & Matthijs de Ligt & $75000000 €$ & 20 & Juventus FC & 213269 & $351,67 €$ \\
\hline 43 & Aymeric Laporte & $75000000 €$ & 25 & Manchester City & 163013 & $460,09 €$ \\
\hline 44 & Marco Verratti & $75000000 €$ & 27 & Paris Saint-Germain & 2088835 & $35,91 €$ \\
\hline 45 & Mauro Icardi & $75000000 €$ & 27 & Paris Saint-Germain & 617614 & $121,44 €$ \\
\hline 46 & Cristiano Ronaldo & $75000000 €$ & 35 & Juventus FC & 126023622 & $0,60 €$ \\
\hline 47 & Gabriel Jesus & $70000000 €$ & 22 & Manchester City & 2835225 & $24,69 €$ \\
\hline 48 & Arthur & $70000000 €$ & 23 & FC Barcelona & 1682361 & $41,61 €$ \\
\hline 49 & Ousmane Dembélé & $70000000 €$ & 22 & FC Barcelona & 517859 & $135,17 €$ \\
\hline 50 & Lucas Hernández & $70000000 €$ & 24 & Bayern Munich & 92313 & $758,29 €$ \\
\hline 51 & José Giménez & $70000000 €$ & 25 & Atlético Madrid & 310400 & $225,52 €$ \\
\hline 52 & Ederson & $70000000 €$ & 26 & Manchester City & 328893 & $212,84 €$ \\
\hline 53 & Fabinho & $70000000 €$ & 26 & Liverpool FC & 184523 & $379,36 €$ \\
\hline 54 & Harry Maguire & $70000000 €$ & 27 & Manchester United & 307207 & $227,86 €$ \\
\hline 55 & Kalidou Koulibaly & $70000000 €$ & 28 & SSC Napoli & 192073 & $364,44 €$ \\
\hline 56 & Philippe Coutinho & $70000000 €$ & 27 & Bayern Munich & 2515546 & $27,83 €$ \\
\hline 57 & Pierre-Emerick Aubameyang & $70000000 €$ & 30 & Arsenal FC & 993716 & $70,44 €$ \\
\hline 58 & Robert Lewandowski & $70000000 €$ & 31 & Bayern Munich & 9034468 & $7,75 €$ \\
\hline 59 & Tanguy Ndombélé & $65000000 €$ & 23 & Tottenham Hotspur & 33516 & $1939,37 €$ \\
\hline 60 & Richarlison & $65000000 €$ & 22 & Everton FC & 106841 & $608,38 €$ \\
\hline 61 & Nicolas Pépé & $65000000 €$ & 24 & Arsenal FC & 28764 & $2259,77 €$ \\
\hline 62 & Marquinhos & $65000000 €$ & 25 & Paris Saint-Germain & 774286 & $83,95 €$ \\
\hline 63 & Jorginho & $65000000 €$ & 28 & Chelsea FC & 30209 & $2151,68 €$ \\
\hline 64 & David Alaba & $65000000 €$ & 27 & Bayern Munich & 4460805 & $14,57 €$ \\
\hline 65 & Miralem Pjanic & $65000000 €$ & 29 & Juventus FC & 999625 & $65,02 €$ \\
\hline 66 & Sergio Agüero & $65000000 €$ & 31 & Manchester City & 10803257 & $6,02 €$ \\
\hline 67 & Achraf Hakimi & $60000000 €$ & 21 & Borussia Dortmund & 388567 & $154,41 €$ \\
\hline 68 & Federico Valverde & $60000000 €$ & 21 & Real Madrid & 216888 & $276,64 €$ \\
\hline 69 & Mikel Oyarzabal & $60000000 €$ & 22 & Real Sociedad & 0 & \\
\hline 70 & Fabián Ruiz & $60000000 €$ & 23 & SSC Napoli & 0 & \\
\hline
\end{tabular}




\begin{tabular}{|c|c|c|c|c|c|c|c|}
\hline TW followers & TW value & IG followers & IG value & $\begin{array}{c}\text { TikTok } \\
\text { followers }\end{array}$ & TT value & SN Reach & SN value \\
\hline 2400000 & $33,33 €$ & 8100000 & $9,88 €$ & 0 & & 13754096 & $5,82 €$ \\
\hline 1100000 & $72,73 €$ & 2400000 & $33,33 €$ & 0 & & 3735387 & $21,42 €$ \\
\hline 937000 & $85,38 €$ & 0 & & 18 & $4444444,44 €$ & 1618591 & $49,43 €$ \\
\hline 24900 & $3212,85 €$ & 716000 & $111,73 €$ & 0 & & 898863 & $89,00 €$ \\
\hline 5800000 & $13,79 €$ & 14000000 & $5,71 €$ & 0 & & 28251352 & $2,83 €$ \\
\hline 657 & $121765,60 €$ & 2600000 & $30,77 €$ & 0 & & 3150312 & $25,39 €$ \\
\hline 16400 & $4878,05 €$ & 3900000 & $20,51 €$ & 0 & & 5002223 & $15,99 €$ \\
\hline 1900000 & $42,11 €$ & 11900000 & $6,72 €$ & 0 & & 20049420 & $3,99 €$ \\
\hline 48300 & $1552,80 €$ & 4900000 & $15,31 €$ & 0 & & 5161569 & $14,53 €$ \\
\hline 240900 & $311,33 €$ & 783000 & $95,79 €$ & 0 & & 1186913 & $63,19 €$ \\
\hline 286000 & $262,24 €$ & 4700000 & $15,96 €$ & 0 & & 7074835 & $10,60 €$ \\
\hline 1300000 & $57,69 €$ & 6400000 & $11,72 €$ & 0 & & 8317614 & $9,02 €$ \\
\hline 83100000 & $0,90 €$ & 208000000 & $0,36 €$ & 194300 & $386,00 €$ & 417317922 & $0,18 €$ \\
\hline 1000000 & $70,00 €$ & 14300000 & $4,90 €$ & 0 & & 18135225 & $3,86 €$ \\
\hline 582800 & $120,11 €$ & 4400000 & $15,91 €$ & 0 & & 6665161 & $10,50 €$ \\
\hline 912200 & $76,74 €$ & 8300000 & $8,43 €$ & 0 & & 9730059 & $7,19 €$ \\
\hline 293300 & $238,66 €$ & 1400000 & $50,00 €$ & 0 & & 1785613 & $39,20 €$ \\
\hline 514100 & $136,16 €$ & 991000 & $70,64 €$ & 0 & & 1815500 & $38,56 €$ \\
\hline 220200 & $317,89 €$ & 1800000 & $38,89 €$ & 0 & & 2349093 & $29,80 €$ \\
\hline 635200 & $110,20 €$ & 1700000 & $41,18 €$ & 0 & & 2519723 & $27,78 €$ \\
\hline 742200 & $94,31 €$ & 1700000 & $41,18 €$ & 0 & & 2749407 & $25,46 €$ \\
\hline 285000 & $245,61 €$ & 1400000 & $50,00 €$ & 0 & & 1877073 & $37,29 €$ \\
\hline 2000000 & $35,00 €$ & 22200000 & $3,15 €$ & 0 & & 26715546 & $2,62 €$ \\
\hline 1400000 & $50,00 €$ & 9300000 & $7,53 €$ & 0 & & 11693716 & $5,99 €$ \\
\hline 1200000 & $58,33 €$ & 16700000 & $4,19 €$ & 3167 & $22102,94 €$ & 26937635 & $2,60 €$ \\
\hline 39100 & $1662,40 €$ & 442000 & $147,06 €$ & 0 & & 514616 & $126,31 €$ \\
\hline 224300 & $289,79 €$ & 2400000 & $27,08 €$ & 0 & & 2731141 & $23,80 €$ \\
\hline 0 & & 940000 & $69,15 €$ & 0 & & 968764 & $67,10 €$ \\
\hline 367300 & $176,97 €$ & 3100000 & $20,97 €$ & 0 & & 4241586 & $15,32 €$ \\
\hline 0 & & 1200000 & $54,17 €$ & 0 & & 1230209 & $52,84 €$ \\
\hline 1800000 & $36,11 €$ & 4800000 & $13,54 €$ & 0 & & 11060805 & $5,88 €$ \\
\hline 502500 & $129,35 €$ & 4900000 & $13,27 €$ & 0 & & 6402125 & $10,15 €$ \\
\hline 13400000 & $4,85 €$ & 12700000 & $5,12 €$ & 0 & & 36903257 & $1,76 €$ \\
\hline 362200 & $165,65 €$ & 2700000 & $22,22 €$ & 0 & & 3450767 & $17,39 €$ \\
\hline 365800 & $164,02 €$ & 2400000 & $25,00 €$ & 0 & & 2982688 & $20,12 €$ \\
\hline 16000 & $3750,00 €$ & 64200 & $934,58 €$ & 0 & & 80200 & $748,13 €$ \\
\hline 74700 & $803,21 €$ & 416000 & $144,23 €$ & 0 & & 490700 & $122,27 €$ \\
\hline
\end{tabular}




\begin{tabular}{|c|c|c|c|c|c|c|}
\hline $\begin{array}{c}\text { Market } \\
\text { value rank }\end{array}$ & Player & Market value & Age & Club & FB followers & FB value \\
\hline 71 & Davinson Sánchez & $60000000 €$ & 23 & Tottenham Hotspur & 47248 & $1269,90 €$ \\
\hline 72 & Federico Chiesa & $60000000 €$ & 22 & ACF Fiorentina & 29536 & $2031,42 €$ \\
\hline 73 & Christian Pulisic & $60000000 €$ & 21 & Chelsea FC & 307946 & $194,84 €$ \\
\hline 74 & James Maddison & $60000000 €$ & 23 & Leicester City & 16678 & $3597,55 €$ \\
\hline 75 & Bruno Fernandes & $60000000 €$ & 25 & Manchester United & 274991 & $218,19 €$ \\
\hline 76 & Milan Skriniar & $60000000 €$ & 25 & Inter Milan & 52096 & $1151,72 €$ \\
\hline 77 & Clément Lenglet & $60000000 €$ & 24 & FC Barcelona & 127360 & $471,11 €$ \\
\hline 78 & Anthony Martial & $60000000 €$ & 24 & Manchester United & 1263300 & $47,49 €$ \\
\hline 79 & Riyad Mahrez & $60000000 €$ & 29 & Manchester City & 2100000 & $28,57 €$ \\
\hline 80 & Niklas Süle & $60000000 €$ & 24 & Bayern Munich & 8817 & $6805,04 €$ \\
\hline 81 & Marcelo Brozovic & $60000000 €$ & 27 & Inter Milan & 57325 & $1046,66 €$ \\
\hline 82 & Lorenzo Insigne & $60000000 €$ & 28 & SSC Napoli & 329698 & $181,98 €$ \\
\hline 83 & Stefan de Vrij & $60000000 €$ & 28 & Inter Milan & 239325 & $250,71 €$ \\
\hline 84 & Thibaut Courtois & $60000000 €$ & 27 & Real Madrid & 5275691 & $11,37 €$ \\
\hline 85 & Alexandre Lacazette & $60000000 €$ & 28 & Arsenal FC & 552123 & $108,67 €$ \\
\hline 86 & Koke & $60000000 €$ & 28 & Atlético Madrid & 1262457 & $47,53 €$ \\
\hline 87 & Thiago & $60000000 €$ & 28 & Bayern Munich & 3360310 & $17,86 €$ \\
\hline 88 & Toni Kroos & $60000000 €$ & 30 & Real Madrid & 12301800 & $4,88 €$ \\
\hline 89 & Houssem Aouar & $55000000 €$ & 21 & Olympique Lyon & 49397 & $1113,43 €$ \\
\hline 90 & Declan Rice & $55000000 €$ & 21 & West Ham United & 0 & \\
\hline 91 & Gianluigi Donnarumma & $55000000 €$ & 21 & AC Milan & 15243 & $3608,21 €$ \\
\hline 92 & Donny van de Beek & $55000000 €$ & 22 & Ajax Amsterdam & 69837 & $787,55 €$ \\
\hline 93 & Youri Tielemans & $55000000 €$ & 22 & Leicester City & 115267 & $477,15 €$ \\
\hline 94 & Memphis Depay & $55000000 €$ & 26 & Olympique Lyon & 2864782 & $19,20 €$ \\
\hline 95 & Wilfried Zaha & $55000000 €$ & 27 & Crystal Palace & 430779 & $127,68 €$ \\
\hline 96 & Luis Alberto & $55000000 €$ & 27 & SS Lazio & 7354 & $7478,92 €$ \\
\hline 97 & Alphonso Davies & $50000000 €$ & 19 & Bayern Munich & 5734 & $8719,92 €$ \\
\hline 98 & Rodrygo & $50000000 €$ & 19 & Real Madrid & 1977454 & $25,29 €$ \\
\hline 99 & Ferran Torres & $50000000 €$ & 20 & Valencia CF & 2814 & $17768,30 €$ \\
\hline \multirow[t]{7}{*}{100} & Nicolò Zaniolo & $50000000 €$ & 20 & AS Roma & 6574 & $7605,72 €$ \\
\hline & Mean & $79550000 €$ & & & 4497404,69 & $1469,94 €$ \\
\hline & Valid Mean with SD+ & $79550000 €$ & & & 4684796,55 & $1469,94 €$ \\
\hline & Valid Median & $70000000 €$ & & & 409673,00 & $154,72 €$ \\
\hline & Valid Standard deviation & $28223173,10 €$ & & & 16847980,19 & $5653,46 €$ \\
\hline & Valid Standard deviation + & $107773173,10 €$ & & & & $7123,40 €$ \\
\hline & Valid Standard deviation - & $51326826,90 €$ & & & & $-4183,53 €$ \\
\hline
\end{tabular}




\begin{tabular}{|c|c|c|c|c|c|c|c|}
\hline TW followers & TW value & IG followers & IG value & $\begin{array}{c}\text { TikTok } \\
\text { followers }\end{array}$ & TT value & SN Reach & SN value \\
\hline 151700 & $395,52 €$ & 601000 & $99,83 €$ & 0 & & 799948 & $75,00 €$ \\
\hline 4214 & $14238,25 €$ & 340000 & $176,47 €$ & 0 & & 373750 & $160,54 €$ \\
\hline 382300 & $156,94 €$ & 2400000 & $25,00 €$ & 14800 & $4054,05 €$ & 3105046 & $19,32 €$ \\
\hline 209600 & $286,26 €$ & 709000 & $84,63 €$ & 0 & & 935278 & $64,15 €$ \\
\hline 377000 & $159,15 €$ & 1700000 & $35,29 €$ & 0 & & 2351991 & $25,51 €$ \\
\hline 0 & & 707000 & $84,87 €$ & 0 & & 759096 & $79,04 €$ \\
\hline 166000 & $361,45 €$ & 1600000 & $37,50 €$ & 0 & & 1893360 & $31,69 €$ \\
\hline 2000000 & $30,00 €$ & 5600000 & $10,71 €$ & 0 & & 8863300 & $6,77 €$ \\
\hline 2100000 & $28,57 €$ & 5000000 & $12,00 €$ & 0 & & 9200000 & $6,52 €$ \\
\hline 2414 & $24855,01 €$ & 618000 & $97,09 €$ & 0 & & 629231 & $95,35 €$ \\
\hline 5978 & $10036,80 €$ & 867000 & $69,20 €$ & 0 & & 930303 & $64,50 €$ \\
\hline 52900 & $1134,22 €$ & 1200000 & $50,00 €$ & 0 & & 1582598 & $37,91 €$ \\
\hline 184500 & $325,20 €$ & 552000 & $108,70 €$ & 0 & & 975825 & $61,49 €$ \\
\hline 2400000 & $25,00 €$ & 6500000 & $9,23 €$ & 5 & $12000000,00 €$ & 14175696 & $4,23 €$ \\
\hline 1300000 & $46,15 €$ & 3100000 & $19,35 €$ & 32 & $1875000,00 €$ & 4952155 & $12,12 €$ \\
\hline 954900 & $62,83 €$ & 2100000 & $28,57 €$ & 0 & & 4317357 & $13,90 €$ \\
\hline 3200000 & $18,75 €$ & 4900000 & $12,24 €$ & 0 & & 11460310 & $5,24 €$ \\
\hline 8000000 & $7,50 €$ & 23700000 & $2,53 €$ & 11 & $5454545,45 €$ & 44001811 & $1,36 €$ \\
\hline 75500 & $728,48 €$ & 335000 & $164,18 €$ & 0 & & 459897 & $119,59 €$ \\
\hline 84600 & $650,12 €$ & 229000 & $240,17 €$ & 0 & & 313600 & $175,38 €$ \\
\hline 141200 & $389,52 €$ & 1700000 & $32,35 €$ & 0 & & 1856443 & $29,63 €$ \\
\hline 34400 & $1598,84 €$ & 1000000 & $55,00 €$ & 0 & & 1104237 & $49,81 €$ \\
\hline 0 & & 286000 & $192,31 €$ & 0 & & 401267 & $137,07 €$ \\
\hline 1400000 & $39,29 €$ & 9200000 & $5,98 €$ & 0 & & 13464782 & $4,08 €$ \\
\hline 884400 & $62,19 €$ & 999000 & $55,06 €$ & 0 & & 2314179 & $23,77 €$ \\
\hline 262100 & $209,84 €$ & 0 & & 0 & & 269454 & $204,12 €$ \\
\hline 49200 & $1016,26 €$ & 632000 & $79,11 €$ & 427200 & $117,04 €$ & 1114134 & $44,88 €$ \\
\hline 352200 & $141,96 €$ & 2700000 & $18,52 €$ & 0 & & 5029654 & $9,94 €$ \\
\hline 21700 & $2304,15 €$ & 129000 & $387,60 €$ & 0 & & 153514 & $325,70 €$ \\
\hline 0 & & 907000 & $55,13 €$ & 0 & & 913574 & $54,73 €$ \\
\hline 2561879,32 & $28559,15 €$ & 9487679,01 & $535,73 €$ & 14153,98 & $3132639,05 €$ & 16561117,00 & $500,07 €$ \\
\hline 2725403,53 & $28559,15 €$ & 9681305,11 & $535,73 €$ & 56615,92 & $3132639,05 €$ & 16561117,00 & $500,07 €$ \\
\hline 441500,00 & $134,23 €$ & 2700000,00 & $26,04 €$ & 0,00 & $22102,94 €$ & 3729320,00 & $20,35 €$ \\
\hline \multirow[t]{3}{*}{9768434,23} & $173950,53 €$ & 26004044,99 & $4722,10 €$ & 131302,39 & $6899395,12 €$ & 49173993,99 & $4526,74 €$ \\
\hline & $202509,68 €$ & & $5257,84 €$ & & $10032034,17 €$ & & $5026,81 €$ \\
\hline & $-145391,38 €$ & & $-4186,37 €$ & & $-3766756,06 €$ & & $-4026,66 €$ \\
\hline
\end{tabular}




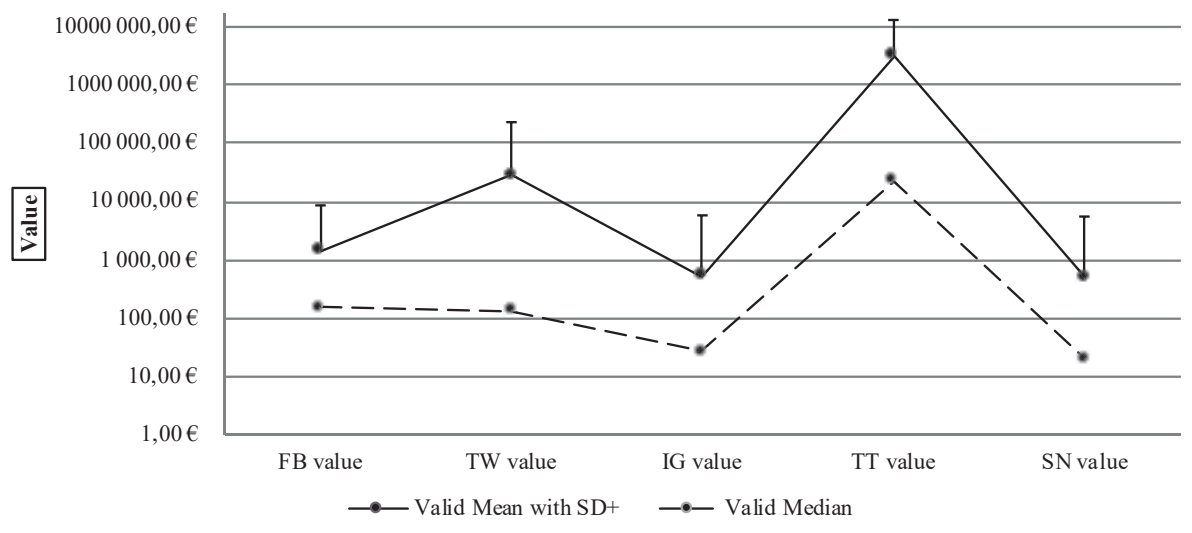




\section{APPENDIX 3}

Estimates of the Potencial TikTok followers for soccer players

\begin{tabular}{l|r|r|r|c}
\hline $\mathbf{2 0 2 0}$ & $\begin{array}{c}\text { Cristiano Ronaldo } \\
\text { followers }\end{array}$ & Users & CR index & $\begin{array}{c}\text { Potential TikTok followers } \\
\text { for soccer players }\end{array}$ \\
\hline Facebook & 126023622 & $2449000000^{*}$ & 0.05146 & 41167373 \\
\hline Twitter & 83100000 & $340000000^{*}$ & 0.24441 & 195529412 \\
\hline Instagram & 208000000 & $1000000000^{*}$ & 0.20800 & 166400000 \\
\hline Modified SN reach & 417123622 & 3789000000 & 0.11009 & 88070440 \\
\hline Unique social media users & & $3800000000^{*}$ & 0.10977 & 87815499 \\
\hline Mean potential & & & 0.14475 & 115796545 \\
\hline TikTok users & & $800000000^{*}$ & & \\
\hline Mohamed Salah TT followers & & 530700 & 0.00066 & \\
\hline Alphonso Davies TT followers & & 427200 & 0.00053 & \\
\hline Cristiano Ronaldo TT followers & & 194300 & 0.00024 & \\
\hline
\end{tabular}

Note: * ${ }^{-}$Statista.com (January 2020); CR index = Cristiano Ronaldo followers/Users. 